\title{
Emergence and Progression of Albuminuria in a Cohort of Egyptian Patients with Type 2 Diabetes Mellitus: a 5-year Prospective Study
}

\author{
Amin R Soliman ${ }^{a^{*}}$, Mohamed Momtaz ${ }^{\mathrm{a}}$, Noha H Shaheen ${ }^{\mathrm{b}}$ \\ Departments of (a) Medicine and (b) Clinical Pathology, Cairo Hospital, Cairo, Egypt
}

\begin{abstract}
Introduction: We sought to report the 5-year incidence of proteinuria and risk factors for the progression of diabetic nephropathy in Egyptians with type 2 diabetes mellitus (DM).
\end{abstract}

Methods: Five-hundred and twelve Egyptians with type 2 diabetes were evaluated at baseline and after five years of follow-up by a timed urine sample to measure urinary albumin excretion. Baseline evaluation included potential risk factors of progression of diabetic nephropathy.

Results: Patients mean age was $47.5 \pm 8.8$ years and $47.6 \%$ of them were males. Their mean duration of diabetes was $8.9 \pm 6.6$ years and $44.1 \%$ of them were on insulin. At baseline, $62.5 \%$ of patients had no proteinuria, $23 \%$ had microalbuminuria and $14.5 \%$ had overt proteinuria. Among patients that had no albuminuria at baseline, $173 / 320$ still had no albuminuria after 5-year follow up (54.1\%), 79/320 developed microalbuminuria (24.7\%) and 68/320 developed macroalbuminuria (21.3\%). Microalbuminuria progressed to macroalbuminuria in $44 / 118$ patients $(37.3 \%)$, and $45 / 512$ patients developed end stage renal disease (8.8\%). Regression from microalbuminuria to no albuminuria occurred in $49 / 118$ patients $(41.5 \%)$, regression from overt proteinuria to microalbuminuria occurred in 16/74 patients $(21.6 \%)$ and regression from overt proteinuria to no albuminuria occurred in $2 / 74$ patients $(2.7 \%)$. In multivariate analysis, only higher baseline albumin excretion rate (OR 1.4, P < $0.002)$, higher blood cholesterol levels (OR 2.5, $\mathrm{P}<0.02)$, and depression $(2.3, \mathrm{P}<0.04)$ remained independently associated with new-onset proteinuria.

Conclusions: In this group of Egyptians with type 2 diabetes, the 5-year incidence of proteinuria is high. Baseline AER is the strongest predictor for incidence of any proteinuria.

\footnotetext{
* Corresponding author; Department of Medicine, Cairo Hospital, 41 Manial street, Cairo 11451, Egypt.

Email: aminroshdy@gmail.com
}

Keywords: Albuminuria; Egyptians; Type 2 Diabetes Mellitus

\section{The authors declared no conflict of interest}

\section{Introduction}

Renal disease represents a major complication for patients with both type 1 and type 2 diabetes mellitus (DM). Diabetic nephropathy affects $20-40 \%$ of those who develop diabetes [1-3] and is associated with enormous morbidity [4, 5], mortality [5] and health care costs [6]. Globally, it is the leading cause of end-stage renal disease (ESRD), accounting for up to $44 \%$ of all cases of ESRD [1]. Racial and ethnic differences in the prevalence and incidence of diabetic nephropathy and diabetic renal failure or ESRD have been well described [5-7].

Proteinuria, of any cause, was identified as a significant predictor of ESRD and reported as a risk factor for cardiovascular or total mortality. Microalbuminuria or "incipient diabetic nephropathy" is one of the initial clinical manifestations of early diabetic nephropathy [8]. The incidence of micro- or macroalbuminuria in type 1 and type 2 diabetic individuals varies greatly among different populations [8-10]. It is unclear whether racial/ethnic differences exist in the prevalence of microalbuminuria when controlling for socioeconomic status in a setting where access to health care is comparable [11-12]. The purpose of the present study is to investigate the 5-year incidence of, and risk factors for, proteinuria in Egyptian subjects with type 2 DM.

\section{Methods}

Patients aged 30 years or older with a diagnosis of type $2 \mathrm{DM}$ were identified from a random review of medical records. Patients on regular dialysis and those who had received a kidney transplant were excluded from the study. Informed written consent was obtained from patients before inclusion in the study. Patient's baseline evaluation included a structured clinical interview to 
obtain detailed medical and ophthalmologic histories, to collect data on socio-demographic factors and smoking status, and to administer the Beck Depression Inventory (BDI). Patients were considered depressed if, at two visits, the BDI score was 14 . Socioeconomic status was classified according to the Goldthorpe and Hope social grading of occupations [13]. Patients were also examined in the eye clinic for evidence of diabetic retinopathy and measurements of their weight, height and blood pressure were obtained. Venous blood was drawn at baseline for measurement of total glycosylated hemoglobin (using high-pressure liquid chromatography; Bio-Rad, Labcorp Laboratory, Hercules, CA); serum creatinine (using the alkaline picrate method); and lipid profile (using an enzymatic assay and separation spectrophotometry; Genzyme Diagnostics, Cambridge, MA). A timed 4-hour urine collection was obtained with the patient at rest at baseline and after five years of follow-up. Urine was assayed for albumin (using a radioimmunology-assay) and creatinine (using the alkaline picrate method, Smith Kline \& Beecham Clinical Laboratory).

Urine collection was considered adequate if the creatinine concentration in the 4-hour urine collection was at least $15-30 \mathrm{mg} / \mathrm{dl}$ for men and $10-15 \mathrm{mg} / \mathrm{dl}$ for women. Urine dipstick testing for nitrites (Chemstrip regent; Boehringer Mannheim) was used to exclude patients with urinary tract infections.

Microalbuminuria was defined as albumin excretion rate (AER) $20-200 \mathrm{mcg} / \mathrm{min}$, while macroalbuminuria was defined as AER $>200 \mathrm{mcg} / \mathrm{min}$. The 5 -year incidence of "any proteinuria", either microalbuminuria or overt proteinuria, was calculated for patients who, at baseline, had an AER $<20 \mathrm{mcg} / \mathrm{min}$. Patients who developed "any proteinuria" were those of this group who, at follow-up, had microalbuminuria (AER 20-200 mcg/min), overt proteinuria (AER $>200 \mathrm{mcg} / \mathrm{min}$ ), were started on dialysis, or received a kidney transplant. Patients who developed microalbuminuria were those of this group who, at follow-up, had an AER 20-200 mcg/min. Patients who developed overt proteinuria were those of this group who, at follow-up, either had an AER >200 $\mathrm{mcg} / \mathrm{min}$, were started on dialysis, or received a kidney transplant. The 5-year progression to overt proteinuria was calculated for all patients who, at baseline, either had no albuminuria or had microalbuminuria but were found, at follow-up, to have overt proteinuria, to be on dialysis, or to have received kidney transplantation. The 5-year incidence of ESRD was calculated for all the study group; patients who developed ESRD were those of this group who, at follow-up, were either on dialysis or had received kidney transplantation. The 5-year incidence of regression of proteinuria was calculated for all patients who, at baseline, had 'any proteinuria'. Patients who regressed were those of this group who, at follow-up, had regressed from microalbuminuria to no proteinuria or from overt proteinuria to either micro- or no proteinuria.

Statistical analyses were performed using the statistical software package SAS, version 9.1. Incidence rates were calculated for the following end points: any proteinuria, microalbuminuria, overt proteinuria, regression of proteinuria, and ESRD. Associations between the incidence of any degree of proteinuria and various baseline characteristics were tested using logistic regression. For dichotomous variables, odds ratios (ORs) were used to quantify the association between any proteinuria and each risk factor. The statistical significance of the associations was based on Wald test. For categorical variables with more than two categories, the ORs are presented for each level of the risk factor, compared with a reference level thought to represent the lowest risk. Multiple logistic regression was used to isolate the impact of specific risk factors in relation to incidence of any proteinuria, controlling for the effect of potential confounders. Models were run including baseline characteristics that were either significant on univariate analysis or likely to contribute to the incidence risk. All tests were two sided and the criterion for statistical significance was $\mathrm{P}<0.05$.

\section{Results}

The study included 512 patients with type 2 diabetes; 226 of whom $(44.1 \%)$ were on insulin. The mean duration of follow-up was $5.1 \pm 0.4$ years and the median follow-up duration was 4.92 years. Table 1 shows the baseline characteristics of the study population.

Table 2 shows the 5-year incidence of proteinuria after five years of follow up among patients with no albuminuria at baseline. Overall, the development of new onset proteinuria and progression of preexisting proteinuria occurred in 191/438 patients at risk (43.6\%), including 147 of 320 patients that had no albuminuria at baseline $(45.9 \%)$, and 44 of 118 patients $(37.3 \%)$ that had microalbuminuria at baseline. In addition, 45/512 patients $(8.8 \%)$ developed ESRD during the 5-year follow up. Regression of proteinuria occurred overall in $67 / 192$ patients $(34.9 \%$ ), including 49 of 118 patients who regressed from microalbuminuria to no albuminuria (41.5\%), 16 of 74 patients who regressed from overt proteinuria to microalbuminuria $(21.6 \%)$ and 2 of 74 patients who regressed from overt proteinuria to no albuminuria $(2.7 \%)$.

The 5-year incidence of any proteinuria was $28.2 \%$ in patients with 5-10 years duration of diabetes at baseline, compared to $45.5 \%$ in patients whose diabetes duration was 10-15 years at baseline. Among patients above 50 years of age, the 5-year incidence of any proteinuria was 
Table 1: Baseline characteristics of the study population $(\mathbf{N}=\mathbf{5 1 2})$

\begin{tabular}{|c|c|}
\hline Baseline characteristic & Value \\
\hline Age (years), mean $\pm \mathrm{SD}$ & $47.5 \pm 8.8$ \\
\hline Male gender, number (\%) & $244(47.6 \%)$ \\
\hline Duration of diabetes (years), mean $\pm \mathrm{SD}$ & $8.9 \pm 6.6$ \\
\hline Body mass index $\left(\mathrm{kg} / \mathrm{m}^{2}\right)$, mean $\pm \mathrm{SD}$ & $32.6 \pm 9.5$ \\
\hline Glycosylated Hemoglobin (\%), mean \pm SD & $9.5 \pm 3.3$ \\
\hline $\operatorname{AER}(\mu \mathrm{g} / \mathrm{min})$, mean $\pm \mathrm{SD}$ & $198.4 \pm 422$ \\
\hline Serum creatinine $(\mathrm{mg} / \mathrm{dl})$, mean $\pm \mathrm{SD}$ & $1.29 \pm 1.7$ \\
\hline GFR $\left(\mathrm{ml} / \mathrm{min} / 1.73 \mathrm{~m}^{2}\right)$, mean $\pm \mathrm{SD}$ & $98.1 \pm 55.2$ \\
\hline Family history of hypertension, number (\%) & $378(73.8 \%)$ \\
\hline Systemic hypertension, number (\%) & $405(79.9 \%)$ \\
\hline Neuropathy, number (\%) & $376(73.5 \%)$ \\
\hline Depression, number $(\%)$ & $253(49.4 \%)$ \\
\hline ACE inhibitor use, number (\%) & $57(11.1 \%)$ \\
\hline \multicolumn{2}{|l|}{ Socioeconomic status, number (\%) } \\
\hline Middle-high & $187(36.5 \%)$ \\
\hline Low & $325(63.5 \%)$ \\
\hline \multicolumn{2}{|l|}{ Education, number (\%) } \\
\hline$<$ high school & $259(50.1 \%)$ \\
\hline$>$ college & $253(49.9 \%)$ \\
\hline \multicolumn{2}{|l|}{ Smoking, number (\%) } \\
\hline Never & $244(47.6 \%)$ \\
\hline Past & $70(13.6 \%)$ \\
\hline Current & $198(38.8 \%)$ \\
\hline \multicolumn{2}{|l|}{ Diuretic use, number (\%) } \\
\hline Never & $297(58 \%)$ \\
\hline Past & $70(13.7 \%)$ \\
\hline Current & $145(28.3 \%)$ \\
\hline \multicolumn{2}{|l|}{ Total cholesterol (mg/dl), number $(\%)$} \\
\hline$<169.49$ & $41(8 \%)$ \\
\hline $169.50-198.79$ & $105(20.5 \%)$ \\
\hline $198.80-236.69$ & $201(39.2 \%)$ \\
\hline$>236.70$ & $165(32.3 \%)$ \\
\hline \multicolumn{2}{|l|}{ Proteinuria, number $(\%)$} \\
\hline Normoalbuminuria & $320(62.5 \%)$ \\
\hline Microalbuminuria & $118(23 \%)$ \\
\hline Overt proteinuria & $74(14.5 \%)$ \\
\hline 'Any protienuria' & $192(37.5 \%)$ \\
\hline
\end{tabular}

Table 2: Five-year incidence of proteinuria in patients with normal urinary albumin excretion at baseline $(\mathrm{N}=320)$

\begin{tabular}{lll}
\hline Status after 5-year follow-up & Number & Percentage \\
\hline No albuminuria & 173 & 54.1 \\
Microalbuminuria & 79 & 24.7 \\
Macroalbuminuria & 68 & 21.3 \\
Any albuminuria & 147 & 45.9 \\
\hline
\end{tabular}

$55 \%$ for men and $43 \%$ for women. In univariate analysis, new-onset proteinuria was significantly associated with the following baseline characteristics: higher AER, higher $\mathrm{HbA1C}$, higher serum cholesterol, higher BMI, hypertension, family history of hypertension, smoking, low socio-economic status and depression (Table 3).

There was no significant association between incidence of any proteinuria and education, insulin dose, peripheral neuropathy, use of diuretics or ACE inhibitors, or diabetic retinopathy.

When baseline characteristics, which were significantly associated with development of any proteinuria in univariate analysis, were included in a multivariate analysis model, the 5-year incidence of any proteinuria was significantly and independently associated with higher baseline AER (OR 1.4, P < 0.002); higher blood cholesterol levels $(2.5, \mathrm{P}<0.02)$; and depression $(2.3, \mathrm{P}$ $<0.04)$.

\section{Discussion}

The results of the present study indicate that the 5-year incidence of new-onset proteinuria (45.9\%), progression of pre-existing proteinuria (43.6\%\%), and ESRD (8.8\%) are high for the studied Egyptians with type 2 diabetes. Higher AER, systemic hypertension, blood cholesterol, smoking, high BMI and depression at baseline were significant risk factors for new-onset proteinuria in this population in univariate analysis. However, only high AER, hypercholesterolemia and depression proved to be independently associated with new-onset proteinuria in multivariate analysis.

While both higher AER and systemic hypertension have been found to be risk factors for incidence of proteinuria, it is unclear whether they are markers for, or are involved in, the pathogenesis of the disease [14]. Hypertensive nephrosclerosis is one of the leading causes of ESRD [15]. Previously published studies $[16,17]$ suggest that the relationship between blood pressure (BP) elevations and renal damage is present even in the earlier stages of renal disease, as defined by the presence of proteinuria. 
Table 3: Risk factors for new-onset proteinuria in the study population in univariate analysis

\begin{tabular}{lll}
\hline Baseline characteristics & Odds Ratio & P value \\
\hline Hypertension & 2.2 & 0.01 \\
Depression & 1.99 & 0.045 \\
Low socioeconomic status & 1.85 & 0.01 \\
High BMI & 1.44 & 0.02 \\
Higher AER & 1.3 & 0.00 \\
Family history of hypertension & 1.23 & 0.04 \\
Smoking status & 1.2 & 0.03 \\
High HbA1C & 1.1 & 0.03 \\
\hline
\end{tabular}

AER: albumin excretion ratio; BMI: body mass index

The fact that even mild BP elevations were associated with proteinuria for this Egyptian population might suggest that normal BP values for Egyptians are not equivalent to those established for Westerns. This might indicate the need to establish BP nomograms specific to the Egyptian population.

In our Egyptian patients, high blood cholesterol was an independent risk factor for any proteinuria, as it was found in other studies [18-21]. In support of this are the similarities between the pathology of glomerulosclerosis and that of atherosclerosis in animal study data, which indicate that increased blood lipids may damage glomeruli [21].

Smoking was reported as an associated factor with microalbuminuria, independent of blood pressure, in a cross-sectional study that included hypertensive and nonhypertensive patients, and in type 1 and type 2 diabetes mellitus [22-24].

An increase in the glomerular filtration rate (GFR) induced by smoking could generate hyperfiltration, a risk factor for progression to chronic renal disease [23]. Furthermore, secretion of vasopressin is increased during smoking, and vasopressin increases GFR inappropriately via changing the activity of tubulo-glomerular feedback [25].

In this study, elevated BMI values were also significantly associated with proteinuria in univariate analysis. In hypertensive and non-hypertensive patients diagnosed with type 2 diabetes mellitus, obesity was associated with microalbuminuria and UAE was significantly higher in the obese patients compared to controls. In addition, UAE has been positively and significantly correlated with body weight. Furthermore, a significant correlation has been observed between body weight loss and a decrease in proteinuria. [26-29].
The mechanisms by which obesity induce renal injury are poorly understood. Obesity is associated with renal hyperfiltration and hyperperfusion. Kidneys from obese subjects exhibit focal glomerulosclerosis and other histological changes similar to those observed in diabetic nephropathy [30-32].

In this study, the incidence of developing proteinuria was greater in men than in women. This is probably due to the prevalence of cigarette smoking, obesity, hypertension and diabetes mellitus in the male population as a whole. This gender difference is further highlighted as men are more likely to progress to renal disease [33]. This study failed to show any association between the incidence of proteinuria and the use of ACE inhibitors. This might be explained by the low utilization rate of these medications (11.1\%).

In the present study, depression was an independent risk factor for new-onset proteinuria. This was previously reported for Caucasian diabetic patients [34]. Similar pathophysiological changes have been described both for patients with depression and for patients with diabetic renal disease. These include abnormalities in coagulation factors and vascular endothelial function, alteration of immune and inflammatory responses, and insulin resistance [35].

Thus, our data suggest that, in addition to blood pressure and glycemic control, weight loss, abstinence of smoking, institution of lipid-lowering agents, and screening for depression might be considered in the management of this population.

Our study has several potential limitations that must be considered in the interpretation of its findings. The first limitation is the basic assumption in these patients that albuminuria and CKD progression are due to diabetic nephropathy and not other glomerular or interstitial 
diseases. This assumption can only be confirmed by renal biopsies, which are not usually done in such cases. A cause-effect relationship cannot be established because the sequence of events between exposure and outcome is not defined. There is also the possibility of selection bias, in the sense that individuals who participated in the study might be more or less likely to manifest the relationships between BP, age, and proteinuria as all are referred to a diabetic nephropathy clinic. The fact that findings were strong and consistent with published reports suggests that bias is less likely.

\section{Conclusion}

The identification of factors associated with proteinuria might lead to the modification of putative risk factors for renal disease. This is of significance, because proteinuria and even microalbuminuria are associated with adverse cardiovascular and renal outcomes, even in non-diabetic populations. Additionally, the determination of factors associated with proteinuria in this population could guide the design of a more focused screening strategy, by identifying individuals at higher risk for abnormalities. Such a targeted prevention strategy could potentially result in the reduction of ESRD in the population at highest risk for its development.

\section{References}

1. Humphrey LL, Ballard DJ, Frohnert PP, Chu CP, O'Fallon WM, Palumbo PJ. Chronic renal failure in noninsulin dependent diabetes mellitus. A population-based study in Rochester, Minnesota. Ann Intern Med. 1989 Nov 15;111(10):788-96.

2. Klein R, Klein BE, Linton KL, Moss SE. Microalbuminuria in a population-based study of diabetes. Arch Intern Med. 1992 Jan;152(1):153-8.

3. Klein R, Klein BE, Moss SE. Incidence of gross proteinuria in older-onset diabetes. A population-based perspective. Diabetes. 1993 Mar;42(3):381-9.

4. Young BA, Maynard C, Reiber G, Boyko EJ. Effects of ethnicity and nephropathy on lower-extremity amputation risk among diabetic veterans. Diabetes Care. 2003 Feb;26(2):495-501.

5. Young BA, Maynard C, Boyko EJ. Racial differences in diabetic nephropathy, cardiovascular disease, and mortality in a national population of veterans. Diabetes Care. 2003 Aug;26(8):2392-9.

6. US Renal Data System. USRDS 1999 Annual Data Report. Bethesda: National Institutes of Health, National Institute of Diabetes and Digestive and Kidney Diseases; 1999.
7. Karter AJ, Ferrara A, Liu JY, Moffet HH, Ackerson LM, Selby JV. Ethnic disparities in diabetic complications in an insured population. JAMA. 2002 May 15;287(19):251927.

8. Mogensen CE. Microalbuminuria predicts clinical proteinuria and early mortality in maturity-onset diabetes. N Engl J Med. 1984 Feb 9;310(6):356-60.

9. Murtaugh MA, Jacobs DR Jr, Yu X, Gross MD, Steffes M; Coronary Artery Risk Development in Young Adults Study. Correlates of urinary albumin excretion in young adult blacks and whites: the Coronary Artery Risk Development in Young Adults Study. Am J Epidemiol. 2003 Oct 1;158(7):676-86.

10. Krop JS, Coresh J, Chambless LE, Shahar E, Watson RL, Szklo M, Brancati FL. A community-based study of explanatory factors for the excess risk for early renal function decline in blacks vs whites with diabetes: the Atherosclerosis Risk in Communities study. Arch Intern Med. 1999 Aug 9-23;159(15):1777-83.

11. Grimm RH Jr, Svendsen KH, Kasiske B, Keane WF, Wahi MM. Proteinuria is a risk factor for mortality over 10 years of follow-up. MRFIT Research Group. Multiple Risk Factor Intervention Trial. Kidney Int Suppl. 1997 Dec;63:S10-4.

12. Pinto-Sietsma SJ, Janssen WM, Hillege HL, Navis G, De Zeeuw D, De Jong PE. Urinary albumin excretion is associated with renal functional abnormalities in a nondiabetic population. J Am Soc Nephrol. 2000 Oct;11(10):1882-8.

13. Goldthorpe J, Hope K. The Social Grading of Occupations: A New Approach and Scale. New York: Oxford University Press; 1974. p. 134-43.

14. Mogensen CE, Hansen KW, Osterby R, Damsgaard EM. Blood pressure elevation versus abnormal albuminuria in the genesis and prediction of renal disease in diabetes. Diabetes Care. 1992 Sep;15(9):1192-204.

15. Klag MJ, Whelton PK, Randall BL, Neaton JD, Brancati FL, Ford CE, Shulman NB, Stamler J. Blood pressure and end-stage renal disease in men. $\mathrm{N}$ Engl $\mathrm{J}$ Med. 1996 Jan 4;334(1):13-8.

16. Multiple risk factor intervention trial. Risk factor changes and mortality results. Multiple Risk Factor Intervention Trial Research Group. JAMA. 1982 Sep 24;248(12):1465-77.

17. Bianchi S, Bigazzi R, Campese VM. Microalbuminuria in essential hypertension: significance, pathophysiology, and therapeutic implications. Am J Kidney Dis. 1999 Dec;34(6):973-95. 
18. Toto RD, Kirk KA, Coresh J, Jones C, Appel L, Wright J, Campese V, Olutade B, Agodoa L. Evaluation of serum creatinine for estimating glomerular filtration rate in African Americans with hypertensive nephrosclerosis: results from the African-American Study of Kidney Disease and Hypertension (AASK) Pilot Study. J Am Soc Nephrol. 1997 Feb;8(2):279-87.

19. Olivarius Nde F, Andreasen AH, Keiding N, Mogensen CE. Epidemiology of renal involvement in newly-diagnosed middle-aged and elderly diabetic patients. Cross-sectional data from the population-based study "Diabetes Care in General Practice", Denmark. Diabetologia. 1993 Oct;36(10):1007-16.

20. Glucose tolerance and mortality: comparison of WHO and American Diabetes Association diagnostic criteria. The DECODE study group. European Diabetes Epidemiology Group. Diabetes Epidemiology: Collaborative analysis Of Diagnostic criteria in Europe. Lancet. 1999 Aug 21;354(9179):617-21.

21. Diamond J. The role of cholesterol in glomerular injury. In: Keane W, editor. Contemporary Issues in Nephrology. 2nd ed. New York: Churchill Livingstone; 1991. p. 109-26.

22. Stegmayr B, Lithner F. Tobacco and end stage diabetic nephropathy. Br Med J (Clin Res Ed). 1987 Sep 5;295(6598):581-2.

23. Orth SR, Stöckmann A, Conradt C, Ritz E, Ferro M, Kreusser W, Piccoli G, Rambausek M, Roccatello D, Schäfer K, Sieberth HG, Wanner C, Watschinger B, Zucchelli P. Smoking as a risk factor for end-stage renal failure in men with primary renal disease. Kidney Int. 1998 Sep;54(3):926-31.

24. Orth SR, Ritz E, Schrier RW. The renal risks of smoking. Kidney Int. 1997 Jun;51(6):1669-77.

25. Bankir L, Bouby N. Vasopressin and urinary concentration: additional risk factors in the progression of chronic renal failure. Am J Kidney Dis. 1991 May;17(5 Suppl 1):20-6.

26. Spangler JG, Konen JC. Hypertension, hyperlipidemia, and abdominal obesity and the development of microalbuminuria in patients with non-insulin-dependent diabetes mellitus. J Am Board Fam Pract. 1996 JanFeb;9(1):1-6.

27. Reid M, Bennett F, Wilks R, Forrester T. Microalbuminuria, renal function and waist:hip ratio in black hypertensive Jamaicans. J Hum Hypertens. 1998 Apr;12(4):221-7.

28. Valensi P, Assayag M, Busby M, Pariès J, Lormeau B, Attali JR. Microalbuminuria in obese patients with or without hypertension. Int J Obes Relat Metab Disord. 1996 Jun;20(6):574-9.

29. Praga M, Hernández E, Andrés A, León M, Ruilope LM, Rodicio JL. Effects of body-weight loss and captopril treatment on proteinuria associated with obesity. Nephron. 1995;70(1):35-41.

30. Ribstein J, du Cailar G, Mimran A. Combined renal effects of overweight and hypertension. Hypertension. 1995 Oct;26(4):610-5.

31. Kasiske BL, Crosson JT. Renal disease in patients with massive obesity. Arch Intern Med. 1986 Jun;146(6):1105-9.

32. United States Renal Data System: International comparisons of ESRD therapy. In: USRDS 1999 Annual Data Report. Bethesda (MD): National Institutes of Health, National Institute of Diabetes and Digestive and Kidney Diseases; 1999. p. 173-84.

33. Van Tilburg MA, McCaskill CC, Lane JD, Edwards CL, Bethel A, Feinglos MN, Surwit RS. Depressed mood is a factor in glycemic control in type 1 diabetes. Psychosom Med. 2001 Jul-Aug;63(4):551-5.

34. Lustman PJ, Clouse RE, Ciechanowski PS, Hirsch IB, Freedland KE. Depression-related hyperglycemia in type 1 diabetes: a mediational approach. Psychosom Med. 2005 Mar-Apr;67(2):195-9.

35. Reddi AS. Pathogenesis of diabetic nephropathy. In: Diabetic nephropathy: theory and practice. East Hanover (NJ): College Book Pub; 2004. p. 179-247.

36. Klag MJ, Whelton PK, Randall BL, Neaton JD, Brancati FL, Ford CE, Shulman NB, Stamler J. Blood pressure and end-stage renal disease in men. N Engl J Med. 1996 Jan 4;334(1):13-8. 